\title{
Ultrasonic Flaw Detection for Quality Assessment of Explosively Clad Plates
}

\author{
Bogumił Wronka \\ Faculty of Civil Engineering, Mechanics and Petrochemistry, Institute of Mechanical Engineering, \\ Warsaw University of Technology, ul. Łukasiewicza 17, 09-400 Płock, Poland \\ Correspondence should be addressed to Bogumił Wronka; wronkab@pw.plock.pl
}

Received 23 May 2013; Revised 29 December 2013; Accepted 2 January 2014; Published 10 March 2014

Academic Editor: Markku Leskela

Copyright (C) 2014 Bogumił Wronka. This is an open access article distributed under the Creative Commons Attribution License, which permits unrestricted use, distribution, and reproduction in any medium, provided the original work is properly cited.

The aim of this work was to study more thoroughly all problems relating to the evaluation of material defects connected with plate quality before and after explosive cladding. During testing great attention was paid to material defects in plates, the reasons for their appearance and possibility of detecting them by means of ultrasonic technique. It was most important to find out which defects were especially dangerous. The results of ultrasonic testing that relate to the quality of initial steel plates are described. Modelled defects of various sizes are ultrasonically tested and analysed. The properties of explosive welded joints and cases of cracks in clad plates are tested. All these data can be helpful in the context of working out criteria relating to the selection of initial plates for cladding.

\section{Introduction}

Steel plates with explosive cladding are used all over the world because of their special properties. The cladding process causes the significant speed at which large areas can be bonded with the cleanness of weld. Welded plates need to be high quality, particularly in safety-critical applications such as in the power, petrochemical, and electrotechnical industries.

Formed clad plates may have material defects, which may be permissible or nonpermissible depending on the application. The quality of plates due to their existing defects can be evaluated well by means of ultrasonic testing. Figure 1 shows that the final quality of clad plate depends on the explosive welding process and the quality of initial metal plates.

Details about the explosive welding process and the quality inspection of plates are given in [1-4]. The typical course of welding is shown in Figure 2. Two successive wave stages of loading and unloading of the both plates occur during the forming of the wavy joint. The normal and tangential forces which form the wavy joint surface act in the collision area. In the backing metal the zone of elastic and plastic strain is $9.75 \mathrm{~mm}$ thick and depends on the welding parameters [3]. Material strained by the explosive loading shows greater strain hardening than rolled material at the same value of strain [2]. The behaviour of materials under conditions of dynamic loading is also described in other published papers [5-7]. Close to the joint surface, at the location of pearlite fields, martensite is sometimes formed. A little bit farther from the joint surface, at a temperature below $773 \mathrm{~K}$ and at a pressure above $13 \mathrm{GPa}$, iron undergoes the phase change $\alpha \rightleftarrows \varepsilon$. Such a phase change may appear in steel as well as in iron.

All this leads to strain hardening of the joint area. The effect of the loading stage is the formed wavy joint, strain hardening, and internal stresses. The unloading stage develops in the joint area possible material discontinuities from the foregoing stage. It sometimes happens that the steel plate cracks during the explosive cladding. This situation is often aggravated by poor quality of initial plates used for cladding.

The typical defects occurring in the initial thick steel plates with respect to the welding process are considered. During explosive loading macro- and microcracks, delaminations and lappings are especially dangerous. Under the influence of an impulse shock wave these defects cause plate damage during the welding process. 


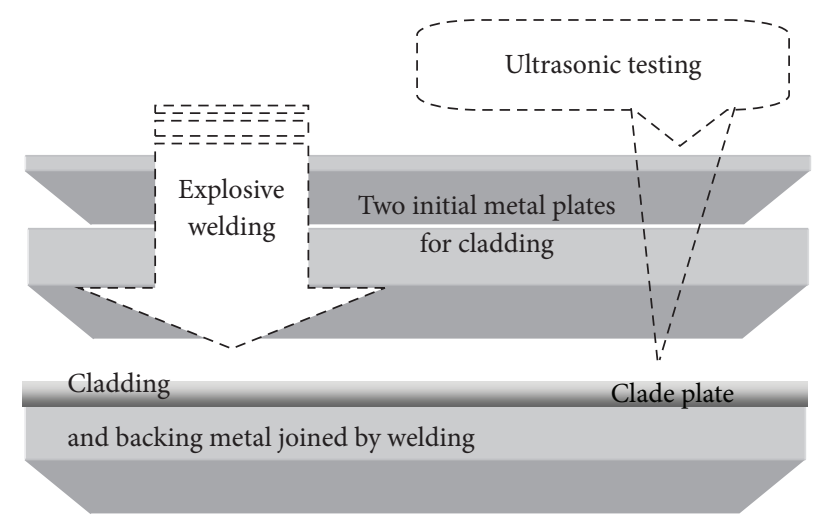

FIGURE 1: Ultrasonic testing used for initial metal plates before cladding and clad plate after explosive welding.

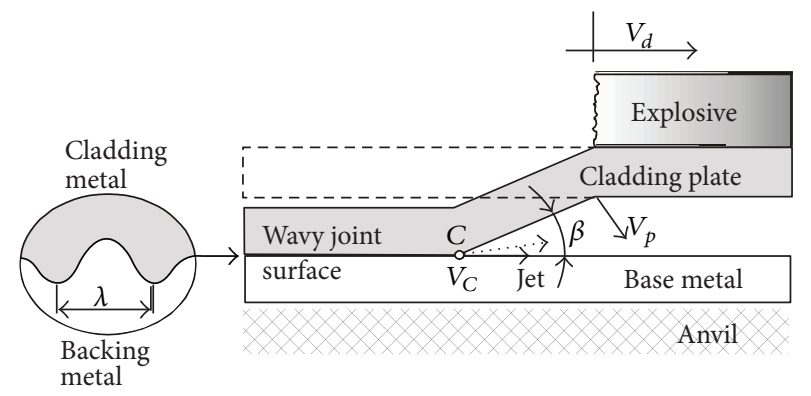

Figure 2: The course of the explosive welding process: $V_{p}$ is the flyer plate velocity, $C$ is the collision point, $V_{C}$ is the collision point velocity, $V_{d}$ is the detonation velocity, $\beta$ is the collision angle, and $\lambda$ is the joint wavelength.

Fast cooling of thick plates within the range of temperatures 473-293 K makes it difficult for hydrogen to be expelled from steel by diffusion. High hydrogen pressure increases the size of existing cracks and causes snowflakes to appear along the plate fibres. This phenomenon lowers the plastic and strength properties of material across its fibres. When the temperature is too high and the heating time is extended, oxygen permeates from the semifinished steel surface to the grain boundaries and a network of hot cracks appears.

The band arrangement of these inclusions and lap slags has a significant influence on the anisotropy and mechanical properties of steel. Insufficient or uneven heating of billets and improper plastic working cause lapping with visible plate layers. Lap blowholes, draw holes, and nonmetallic inclusions are the reasons for plate delaminations.

The ultrasonic technique takes into account different types of material defects. The following types of material defects can be discriminated: point, elongated, large, and multiple [8]. The type of defect is determined on the basis of the maximum echo height of the indication from a defect, the directional dependence of the echo amplitude, and the static and dynamic envelope of the echo height indication $[9,10]$. The example of the point defect is shown in (Figure 3(a)). The principles of such testing for plate inspection are presented in the literature [11-13].
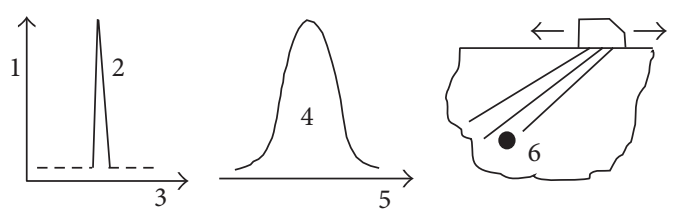

(a)

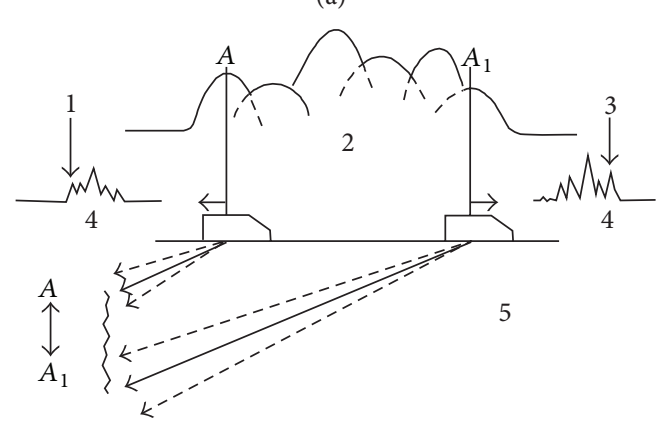

(b)

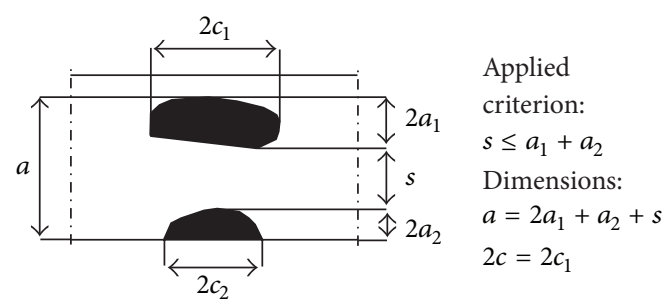

(c)

FIgURE 3: The ultrasonic echo responses of the point defect (a) 1 amplitude, 2 A scan (static envelope), 3 range, 4 variation of peak signal amplitude (dynamic envelope), 5 probe position, and 6 reflector; beam axis tip location technique (b) 1 and 3 echoes $A$ and $A_{1}$ at maximum heights, 2 variation of peak signal amplitude, $4 \mathrm{~A}$ scan and 5 echoes $A$ and $A_{1}$ will be the first to appear when probe is moved backward and forward; the dimensions of substitute crack (c).

The assessment of defect size with manual testing is based on the maximum echo height techniques (DGS and DAC) and probe movement sizing techniques [8] (Figure 3(b)). If cracks lie close to each other (Figure 3(c)) one establishes the size of a substitute crack [14].

The later contents of this paper refer to more difficult to detect small defects. For a small reflector the proportionality of the echo height indication $h_{r}$ and the acoustic pressure $p$ is generally known for an equivalent defect, that is, flat defect normal to the ultrasonic beam. These and other acoustic parameters such as the initial acoustic pressure $p_{0}$, the flat reflector surface area $S_{r}$ with diameter $d$, the transducer surface area $S_{t}$, the wavelength $\lambda$, and the distance $l$ give the following [11]:

$$
h_{r} \sim p=p_{0} \frac{S_{r} S_{t}}{\lambda^{2} l^{2}}
$$

For the assessment of real defects their experimental shape factors are needed.

The knowledge about the relationship between crack size and object load is given by the fracture mechanics [15]. 


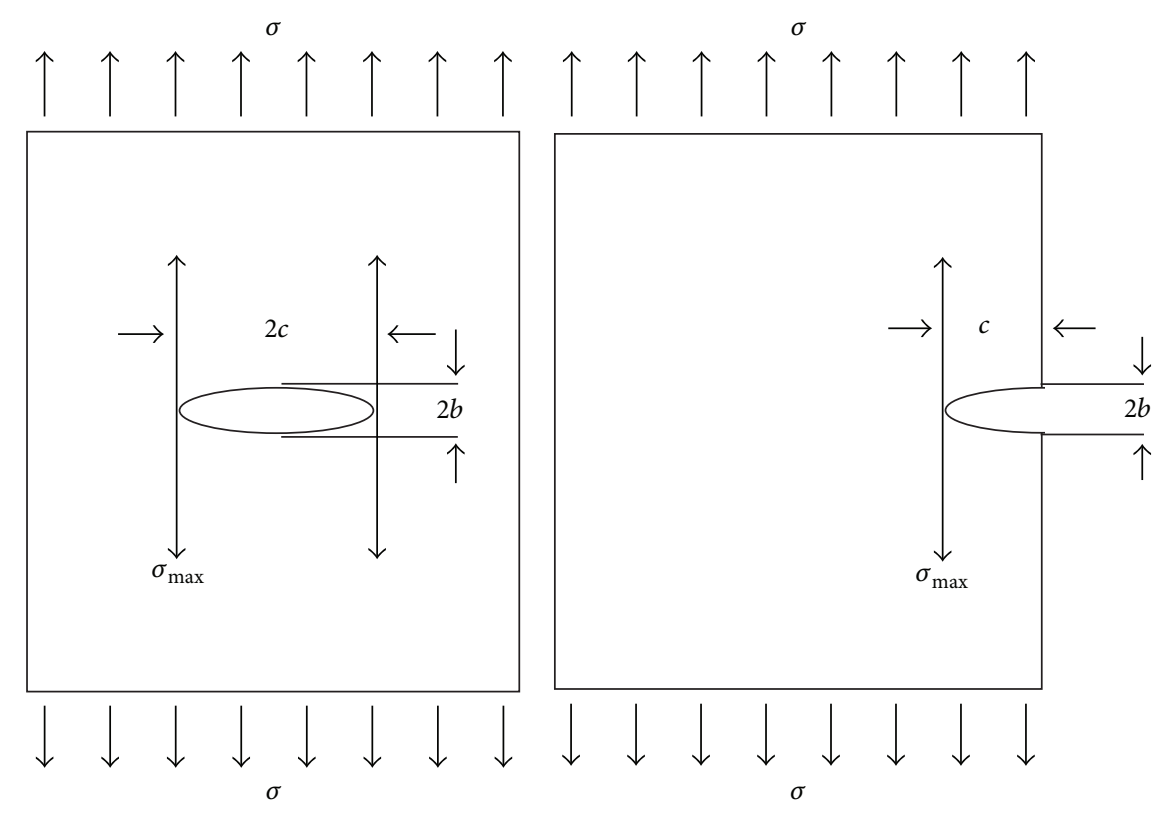

(a)

(b)

FIGURE 4: Maximum stress distribution $\sigma_{\max }$ in a steel plate with an internal crack (a) and an external crack (b) caused by stresses $\sigma$.

The stress distribution in a modelled plate with an elliptic microcrack of dimensions $b, c$ and a radius of curvature $\rho$ at the ends of the major axis were considered (Figure 4). The stress-concentration factor $\alpha$ according to Inglis's suggestion $[14,16]$ is as follows:

$$
\alpha=\frac{\sigma_{\max }}{\sigma}=1+\frac{2 c}{b}=1+2\left(\frac{c}{\rho}\right)^{1 / 2} .
$$

The factor $\alpha$ is minimised for a circle $(c=b)$ and increases for a flat ellipse $(c \gg b)$. Its greatest values occur for natural microcracks, when the radius value $\rho$ reaches the interatomic distance $a$. In welded conditions spherical point defects are less harmful.

The typical defects occur in material before cladding as well as in clad products. An abnormal course of the explosive welding process is able to create subsequent defects in the specifically formed joints.

In this paper there was carried out a model spatial visualization of the typical defects surfaces with the purpose of attaining their better detectability and usefulness of ultrasonic technology.

\section{Results}

2.1. The Modelling of Small Material Defects. The criteria which admit an initial plate for cladding should be based on the fracture mechanics. Moreover, it is essential to know the loading and unloading stages of the plates during the explosive cladding as well as the types and sizes of defects. Therefore, the results of ultrasonic testing of modelled defects of various types and sizes were analyzed. The results of these tests will allow a better assessment of the quality of initial and clad plates.
The reflector types: flat bottom hole, hemispherical bottom hole, and side drilled hole (transverse hole) were models of a planar point defect, spherical point defect, and cylindrical elongated defect, respectively. The beam of ultrasonic waves with a far field (Fraunhofer zone) was reflected from these reflectors. The first two reflector surfaces were equal to a circular surface $S 1=\pi d^{2} / 4$ and a hemispherical surface $S 2=\pi d^{2} l /[2(l+0.5 d)]$, respectively (Figure 5).

The third reflector had the cylindrical surface $S 3$. The quarter of that surface limited by the cone (Figure 6(a)) was calculated by means of the contour integral $\int_{L} y(x, z) \mathrm{d} L$. The curve $L$ was expressed by means of the parametric equations:

$$
L: \begin{cases}x(t)=0.5 d \cos (t) & \\ z(t)=0.5 d[1+\sin (t)] & \text { for } \alpha \leq t \leq \pi / 2 .\end{cases}
$$

After determining $r=0.5 d(1+d / l)^{1 / 2}$ and $z_{0}=d+l$ (Figure 6(a)), and the following transformations, the cone surface $y(x, z)$ was calculated for $y \geq 0$ :

$$
\begin{gathered}
\frac{x^{2}}{r^{2}}+\frac{y^{2}}{r^{2}}=\frac{\left(z-z_{0}\right)^{2}}{\left(z_{0}\right)^{2}}, \\
y(x, z)=\sqrt{\frac{r^{2}}{\left(z_{0}\right)^{2}}\left(z-z_{0}\right)^{2}-x^{2},} \\
y(x, z)=\sqrt{\frac{d^{2}}{4 l(d+l)}\left(z-z_{0}\right)^{2}-x^{2} .}
\end{gathered}
$$




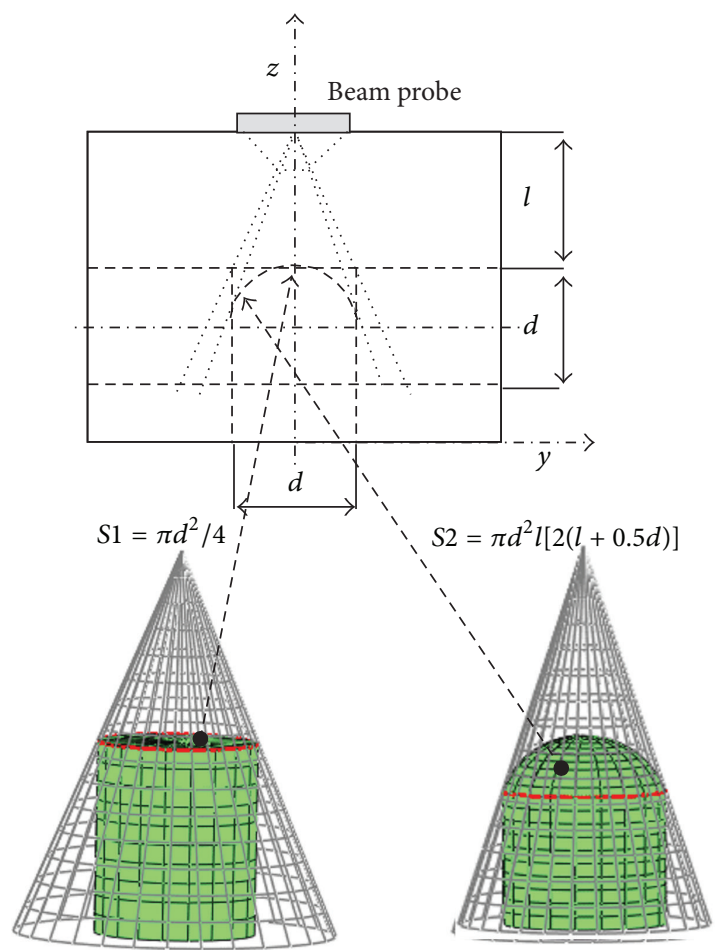

FIGURE 5: The reflector surfaces $S 1$ and $S 2$ which are surrounded by a red line relating to flat bottom hole and hemispherical bottom hole, respectively.

The complete cylindrical surface $S 3$ was calculated after converting the contour integral into the definite integral:

$$
\begin{aligned}
S 3 & =4 \int_{L} y(x, z) \mathrm{d} L \\
& =4 \int_{\alpha}^{\pi / 2} y[x(t), z(t)] \sqrt{\left[x^{\prime}(t)\right]^{2}+\left[y^{\prime}(t)\right]^{2}} \mathrm{~d} t .
\end{aligned}
$$

After including the above data the complete surface size $S 3$ equals

$$
\begin{gathered}
S 3=2 d \int_{\alpha}^{\pi / 2}\left(\frac{d^{2}}{4 l(l+d)}[l+0.5 d-0.5 d \sin (t)]^{2}\right. \\
\left.-[0.5 d \cos (t)]^{2}\right)^{1 / 2} \mathrm{~d} t
\end{gathered}
$$

The reflection surface profile $S 3$ is presented in Figure 6(b).

The dependence of the reflector surfaces $S 1-S 3$ on diameter $d$ is presented in Figure 7.

The above arguments were tested on three modelled steel bars. Each had eight hole reflectors of the same type with diameters ranging from $\varnothing 1$ to $\varnothing 8 \mathrm{~mm}$. The following holes were made: eight flat bottom holes, eight hemispherical bottom holes, and eight side drilled holes. The pictorial diagram of the holes configuration in steel bars and the location of the probe are shown in Figure 8. The reflectors were tested with the far field beam $(l=28 \mathrm{~mm})$. The reflector

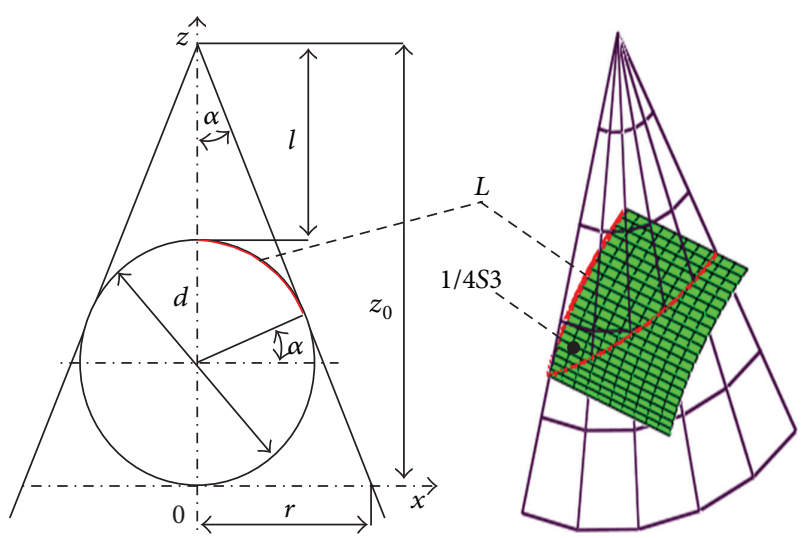

(a)

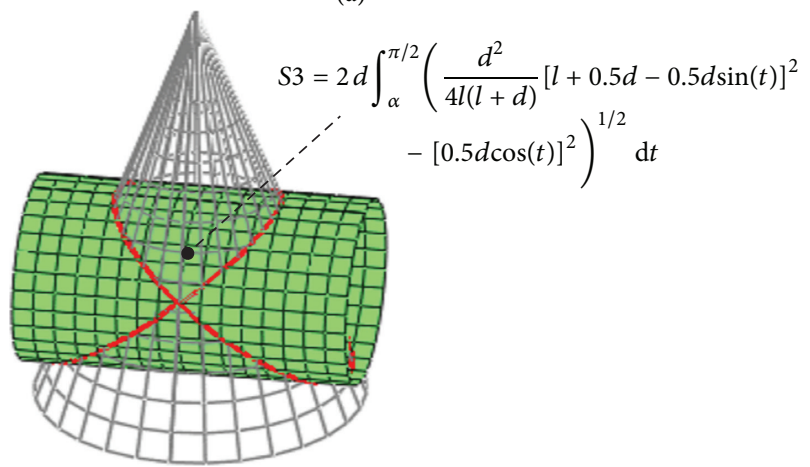

(b)

FIGURE 6: Integral limits for the quarter of the cylindrical surface $S 3$ surrounded by a red line (a) and the surface profile $S 3$ surrounded by a red line in the upper part of the cylinder (b).

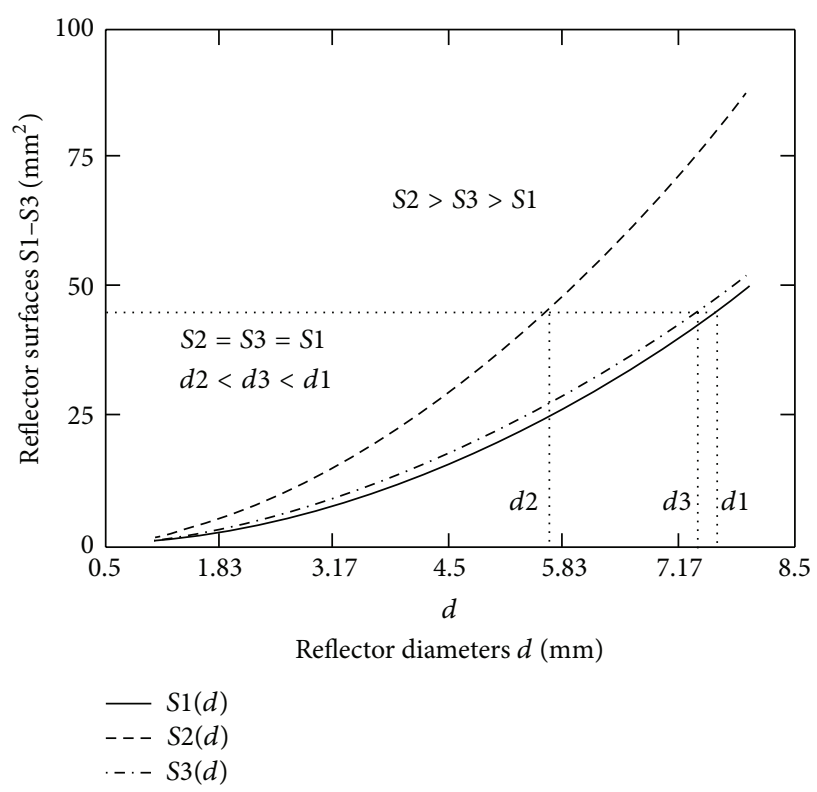

FIGURE 7: The dependence of reflector surfaces $S 1-S 3$ on their reflector diameters $d$. 


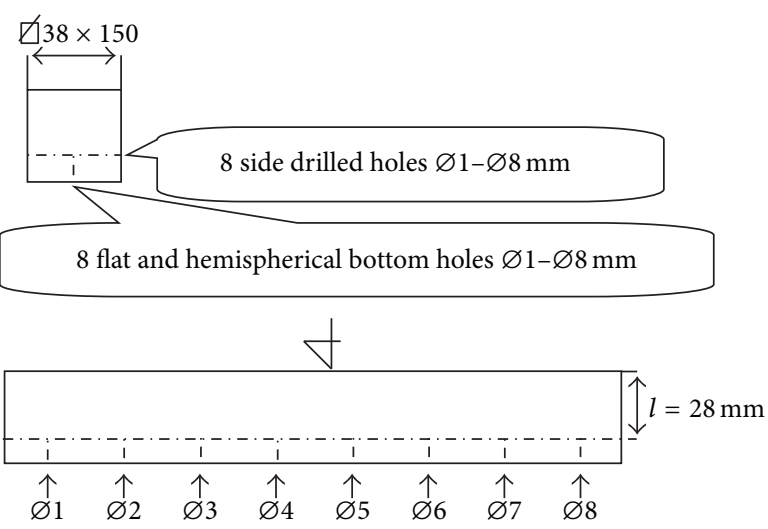

FIGURE 8: Pictorial diagram of the hole configuration in the steel bars.

diameters $d$ were named real defects. The equivalent reflector sizes (defects) resulted from measurement with the DGS technique.

For the testing of the equivalent reflectors the ultrasonic flaw detector USM 25S and the probe MB4S made by Krautkrämer were used. A backwall was used as a reference reflector. The mean values of the three measured results are presented in Figure 9.

The ultrasonic oscillograph records are presented in Figure 10.

\subsection{Test Results for Clad and Initial Plates}

2.2.1. The Material Properties in the Joint Area. Later tests aimed at the evaluation of the properties of clad and initial plates. An example of the macrostructure of the explosive welded joint is presented in Figure 11. It is the wavy aluminium-duralumin joint from the carbon steelaluminium-duralumin clad plate. Such clad plates find their application in the shipbuilding industry.

The macrostructure shows that both materials present significant strain in the joint area. In spite of that there are no signs of material discontinuity.

Additionally, the material strain hardening in the joint area was tested by a relative increase in the Vickers hardness $h=\left(\mathrm{HV}-\mathrm{HV}_{0}\right) / \mathrm{HV}_{0}$. $\mathrm{HV}$ and $\mathrm{HV}_{0}$ are values of the Vickers hardness of the material after welding and in the initial state. The relative increase in the hardness $h$ for the carbon steelbrass joint is presented in Figure 12.

2.2.2. Cracks in the Clad Plates. Defective clad plates resulted from the defective initial plates. In order to prove this a clad plate with a network of cracks at the edges was examined (Figure 13). These cracks occurred during the welding process as a result of the existing defects in the initial steel plate.

2.2.3. Results of Initial Plates before Welding. In one of the modern European steel mills 6-60 mm thick steel plates were tested ultrasonically. The obtained results (European Standard EN 10160) for quality grade $S_{0}$ and $S_{2}$ are presented in

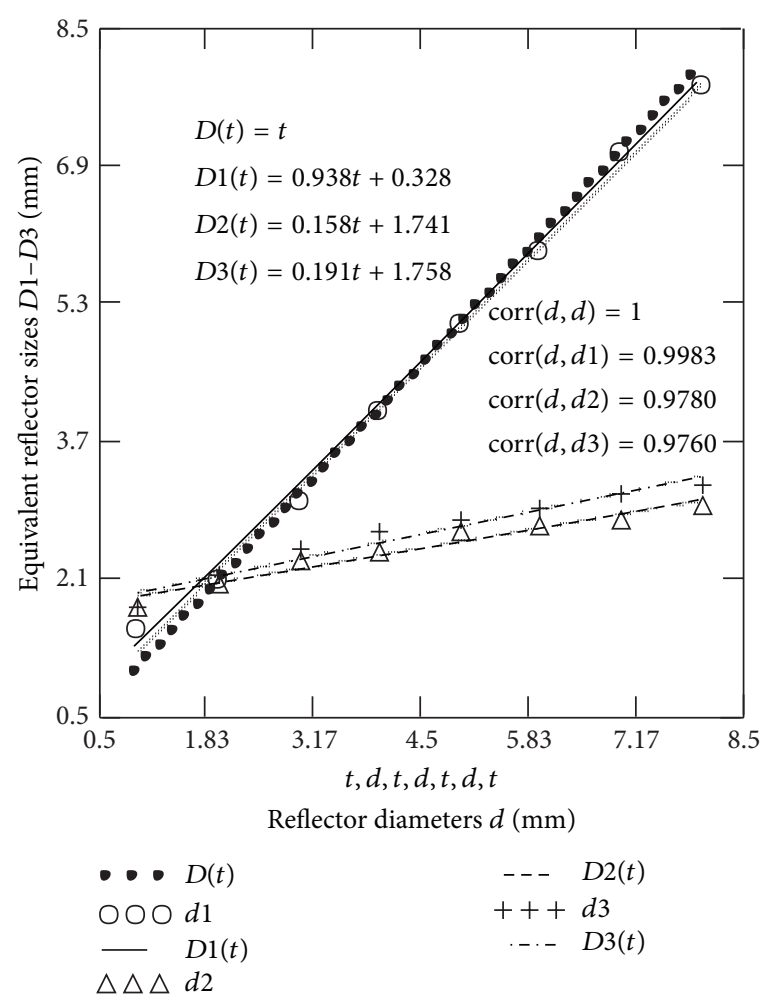

FIGURE 9: The experimental correlation (corr) of sizes: reflector diameters $d$ (real defects) and equivalent reflector sizes (equivalent defects) $D 1(t)-D 3(t) ; D 1(t), D 2(t)$, and $D 3(t)$ relating to flat bottom hole, hemispherical bottom hole and side drilled hole, respectively; $D(t)$ is the theoretical run; $t$ is the programme step $\left(1 \cdot 10^{-4}\right)$ within the range of $d=1-8 \mathrm{~mm}$.

Figure 14. These data showed cracks in the places of hydrogen segregation (dark cylinders and cones). The greatest number of defects $\left(17.2 \%\right.$, grade $\left.S_{2}\right)$ can be found in steel plates with a bigger thickness (41-50 $\mathrm{mm}$ thick). Initial steel plates even above $100 \mathrm{~mm}$ thick can be welded.

\section{Discussion}

The sizes of real surfaces reflecting ultrasonic wave beam were evaluated, which is the original author's solution. However, the sizes of equivalent defects were evaluated in compliance with the assumptions in the literature $[8,11]$.

In the range of the applied real diameters $d$ and lengths $l$ the dimensions courses of the reflected surfaces $S 1-S 3$ were obtained, which satisfy the condition $S 2>S 3>S 1$ (Figure 7). The equality of the tested surfaces $S 2=S 3=S 1$ occurs for the condition of the diameters dimensions $d 2<d 3<d 1$. The smaller the diameter $d$, the smaller the difference between the surfaces dimensions $S 1-S 3$. That property occurs also in the courses of equivalent reflector sizes from the results of ultrasonic testings though the other functions circumscribe them (Figure 9).

The test results for the flat bottom reflectors $(\operatorname{corr}(d, d 1)=$ $0.9983)$ show the greatest convergence with the theoretical run $(\operatorname{corr}(d, d)=1)$ (Figure 9). Significant differences can be 


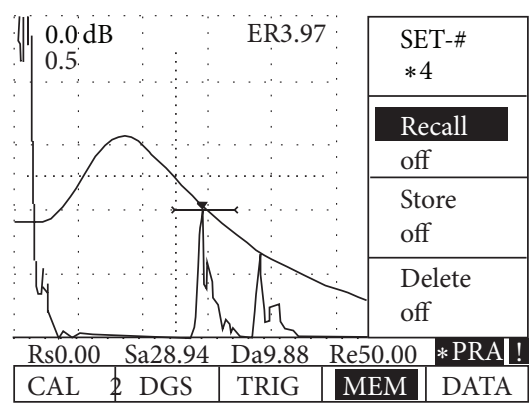

(a)

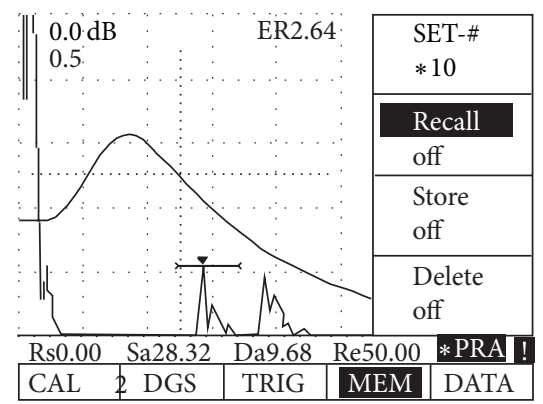

(b)

FIGURE 10: The ultrasonic oscillograph records of two reflectors with diameter $d=4 \mathrm{~mm}$ and a backwall as a reference reflector: you can see equivalent reflector size $\mathrm{ER}=3.97 \mathrm{~mm}$ for flat bottom hole (a) and side drilled hole with $\mathrm{ER}=2.64 \mathrm{~mm}$ (b); DGS curve refers to $\emptyset 4 \mathrm{~mm}$.

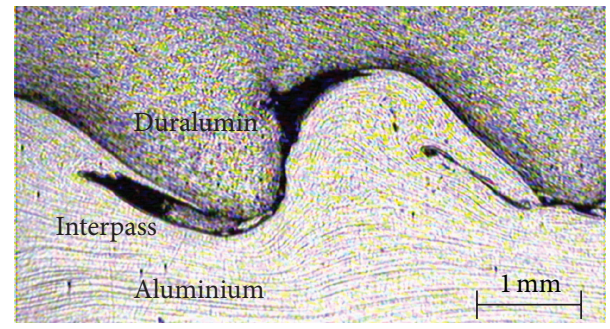

Figure 11: The macrostructure of the aluminium-duralumin joint area, showing the wavy joint with interpass and significantly deformed joint boundary layers of both welded materials.

observed for the hemispherical bottom $(\operatorname{corr}(d, d 2)=0.9780)$ and side drilled $(\operatorname{corr}(d, d 3)=0.9760)$ reflectors. The static envelopes of the echo height indications from the reflectors in the gates testify to the shape differences of the tested reflectors (Figure 10).

Obtained results as shown in Figures 11 and 12 testify to structural and strain hardening changes in the welded joint area. There exists a convergence of the test results with data in the papers $[2,6]$.

If in the joint area of welded materials the plasticity margin will be exceeded then, micro- and macrocracks can appear most often. The cracks that started in the initial plates reveal for good in the clad plates in Figure 13. Therefore, the initial plates for explosive cladding should not be applied with inadmissible defects sizes which form in different production stages of those metallurgic products (Figure 14).

In this paper the cracks detectable with a wave ultrasonic beam referred to flat bottom holes (Figures 5 and 7-9).

\section{Analysis}

The analysis of all tests was carried out with respect to interdepending factors determining the final quality of the clad plate (Figure 1). Despite the fact that the ultrasonic tests were conducted on modelled samples they complied with standard procedures and material used in the production of clad plates. The obtained test results can assist in better detection and interpretation of defects in initial and clad plates.

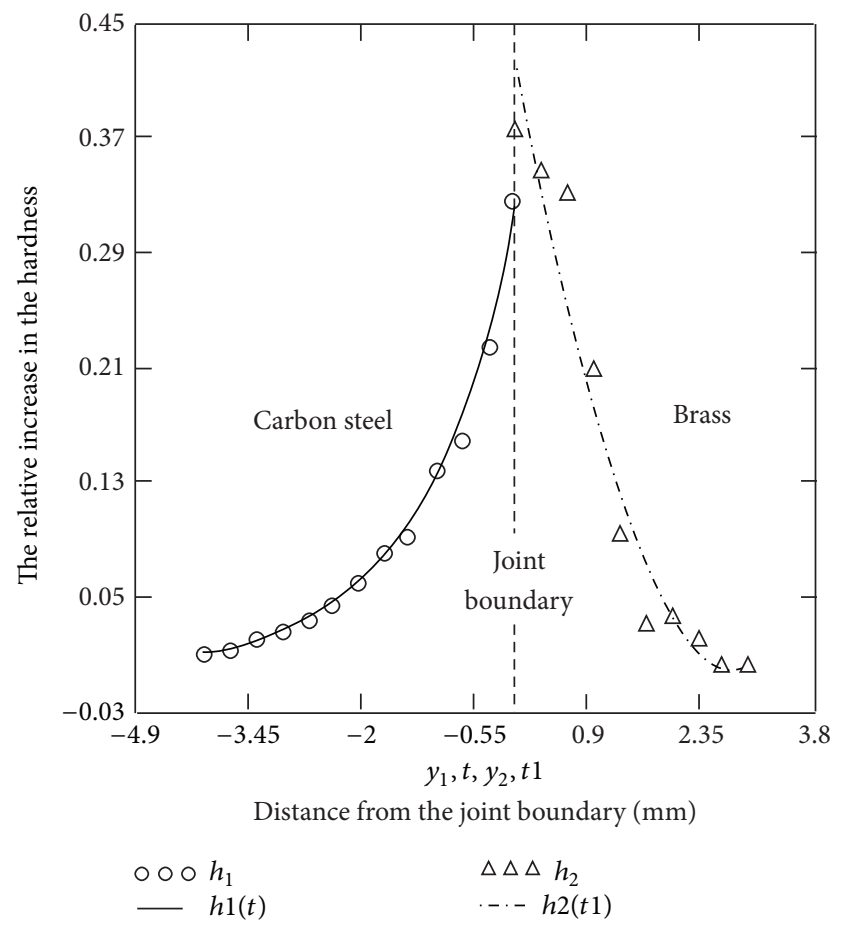

FIGURE 12: The relative increases $h_{1}$ and $h_{2}$ of the hardness as a function of distances $y_{1}$ and $y_{2}$ from the joint boundary for the carbon steel-brass joint; $h 1(t)$ and $h 2(t 1)$ are curves smoothed by a loess procedure.

Finally, the ultrasonic testing results confirmed theoretical assumptions. In the case of a flat bottom reflector the echo height indication $h_{r}$ is proportional to its reflector surface area $S_{r}(1)$ [11]. In the cases of hemispherical bottom and side drilled reflectors the interdependence is different. It is the result of smaller acoustic pressures $p 2<p 3<p 1$ in spite of bigger reflector surfaces $S 2>S 3>S 1$ (Figure 7). Equation (6) referring to the surface $S 3$ was useful for the comparative evaluation. 

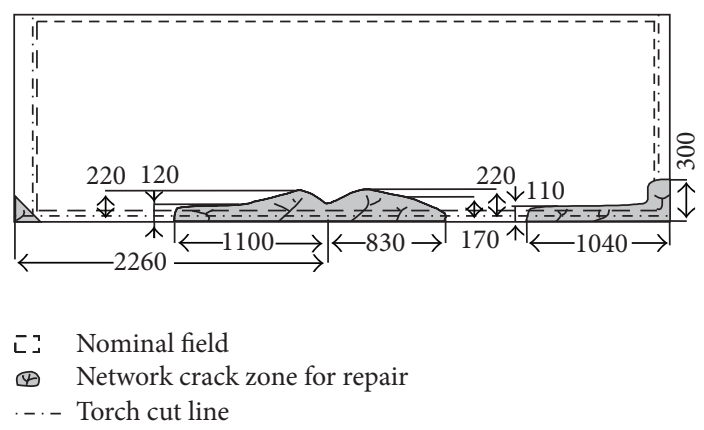

FIGURE 13: The clad plate made of carbon steel (34 mm thick, grades $S_{2}$ and $\left.E_{0}\right)$ and duplex steel $(6 \mathrm{~mm}$ thick) after ultrasonic testing (ASME SA 578), showing crack networks at edges and vertexes in the carbon steel plate.

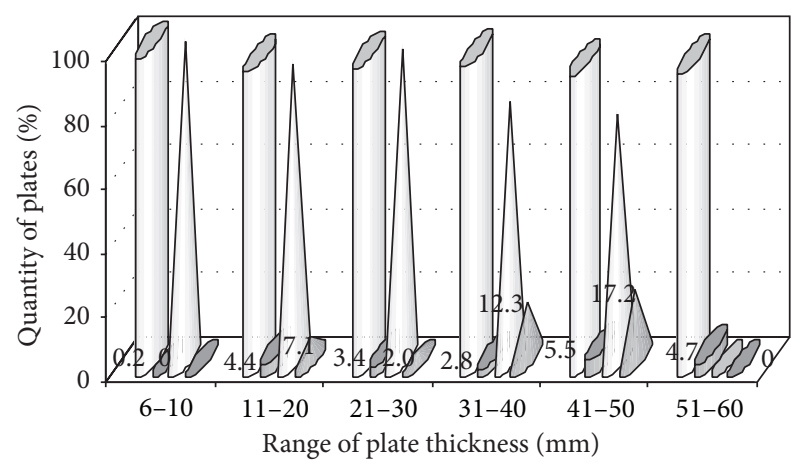

FIGURE 14: The division of test plates according to accepted criteria: grade $S_{0}$ (cylinders) and grade $S_{2}$ (cones), accepted (light) and defective (dark, $0-17.2 \%)$ plates.

In the DGS method [8] the most correlation between real and equivalent defects was discovered in case of the flat bottom reflector (Figure 9). The reflector models a crack as a defect that is the most dangerous for the welded plates with the loading and unloading stages (2). With a backwall as a reference reflector the equivalent reflector sizes for hemispherical bottom and side drilled reflectors are significantly smaller than their real sizes.

The aluminium-duralumin wavy joint is of a complex internal structure (Figure 11). Beside the direct joint there exist also the segments of interpass. The layers of both adherent materials to the joint boundary are clearly deformed without the loss of cohesion. This area shows strain hardening which is confirmed by the relative increase in the Vickers hardness (Figure 12).

In the clad plate cracks can occur from the borders of the steel plate of a low quality grade $E_{0}$ (Figure 13). Enlargement of those cracks is especially evident in the thick plates of larger brittleness. The regions with such cracks require further corrections of the clad plate before their use. The greatest number of cracks was found in thick steel plates when they were tested with ultrasonic technique (Figure 14). These thick plates are commonly used for explosive cladding.

In order to obtain the right quality of clad plates, good quality initial plates must be used. The poor quality of the initial plates with nonpermissible cracks is often the main cause of their destruction during explosive cladding. The material properties in the joint area as well as cracks must be included in the selection criteria of the initial plates (Figure 1).

\section{Conclusions}

Analysis of test results facilitated presentation of these conclusions.

(i) The ultrasonic technique allows detecting types and sizes of material defects in plates before and after cladding. In case of a greater number of cracks it is possible to calculate a substitute crack for the fracture mechanics.

(ii) When the defect diameters $d$ are the same, the curvilinear surfaces of the defects are larger than the flat surface of the defect. However, the ultrasonic wavy beam reflected from the diffusing surfaces gives a smaller echo height indication than in the case of a flat defect. The value of acoustic pressure always determines the echo height indication from a defect.

(iii) In the DGS method the correlation between the size of the real and equivalent defect is the largest for the flat surface defect which models the most dangerous crack defect. The smaller correlation of those results was obtained for the defects with curvilinear surfaces.

(iv) The typical joint area of the explosive clad plate includes the wavy joint surface without or with segments of the interpass. Strain hardened layers of both materials have a limited or an exhausted plasticity and are not deprived of their internal stresses. This joint area is the result of the explosive cladding of the initial plates.

(v) In case of an inadequate selection of the initial plates with a low quality grade of the borders one can expect cracks in the clad plate.

(vi) Only the initial plates of adequate quality, that is, with permissible defects, should be explosively welded. It refers mostly to thick plates with greater brittleness. It this way the destruction of expensive clad plates during the welding process can be prevented.

(vii) The explosive welding process, the plate quality after welding, and application of the fracture mechanics should be employed to ascertain the criteria for quality selection of the initial plates ready for cladding.

\section{Conflict of Interests}

The author declares that there is no conflict of interests regarding the publication of this paper.

\section{References}

[1] T. Z. Blazynski, Explosive Welding Forming and Compaction, Applied Scientific, New York, NY, USA, 1983. 
[2] A. A. Deribas, Fizika Uprocznenija i Svarki Vzryvom, Nauka, Novosibirsk, Russia, 1980.

[3] B. Wronka, "Testing of explosive welding and welded joints. Wavy character of the process and joint quality," International Journal of Impact Engineering, vol. 38, no. 5, pp. 309-313, 2011.

[4] I. Plaksin, J. Campos, J. Ribeiro et al., "Novelties in physics of explosive welding and powder compaction," in Proceedings of the 7th International Conference on Mechanical and Physical Behaviour of Materials under Dynamic Loading (Eurodymat '03), pp. 797-802, Porto, Portugal, September 2003.

[5] B. Wronka, "Testing of explosive welding and welded joints: Joint mechanism and properties of explosive welded joints," Journal of Materials Science, vol. 45, no. 15, pp. 4078-4083, 2010.

[6] B. Wronka, "Acoustic and mechanical anisotropy in the testing of explosively welded joints," Insight, vol. 52, no. 11, pp. 603-608, 2010.

[7] V. Favier, S. Berbenni, X. Lemoine, and M. Berveiller, "Dynamic behaviour of steels: an elastic-viscoplastic micro-macro polycrystalline approach," in Proceedings of the 15th Dymat Technical Meeting, Crashworthiness and Constitutive Relationships for Engineering Materials, pp. 51-56, LPMM-University of Metz, Metz, France, 2004.

[8] European Standard EN 583-5, "Non-Destructive TestingUltrasonic Examination-Part 5, Characterization and Sizing of Discontinuities," 2000.

[9] European Standard EN 583-2, "Non-Destructive TestingUltrasonic Examination-Part 2, Sensivity and Range Setting," 2000.

[10] European Standard EN 1713, "Non-Destructive Examination of Welds-Ultrasonic Examination-Characterization of Indications in Welds," 1998.

[11] J. Krautkramer and H. Krautkramer, Ultrasonic Testing of Materials, Springer, New York, NY, USA, 4th edition, 1990.

[12] C. H. Gür and Y. Keleş, "Ultrasonic characterisation of hotrolled and heat-treated plain carbon steels," Insight, vol. 45, no. 9, pp. 615-620, 2003.

[13] K. Yamanaka, T. Mihara, and T. Tsuji, "Evaluation of closed cracks by analysis of subharmonic ultrasound," Insight, vol. 46, no. 11, pp. 666-670, 2004.

[14] M. Koçak, S. Webster, J. J. Janosch, R. A. Ainsworth, and R. Koers, FITNET, Fitness-for-Service, GKSS Research Centre Geesthacht GmbH, 2008.

[15] T. L. Anderson, Fracture Mechanics: Fundamentals and Applications, CRC Press, 3rd edition, 2000.

[16] C. E. Inglis, "Stress in a plate due to the presence of cracks and sharp corners," Transaction of the Institution of Naval Architects, vol. 55, pp. 219-230, 1913, (Reprinted in Fracture Mechanics Retrospective, ASTM RPS 1, 1987). 

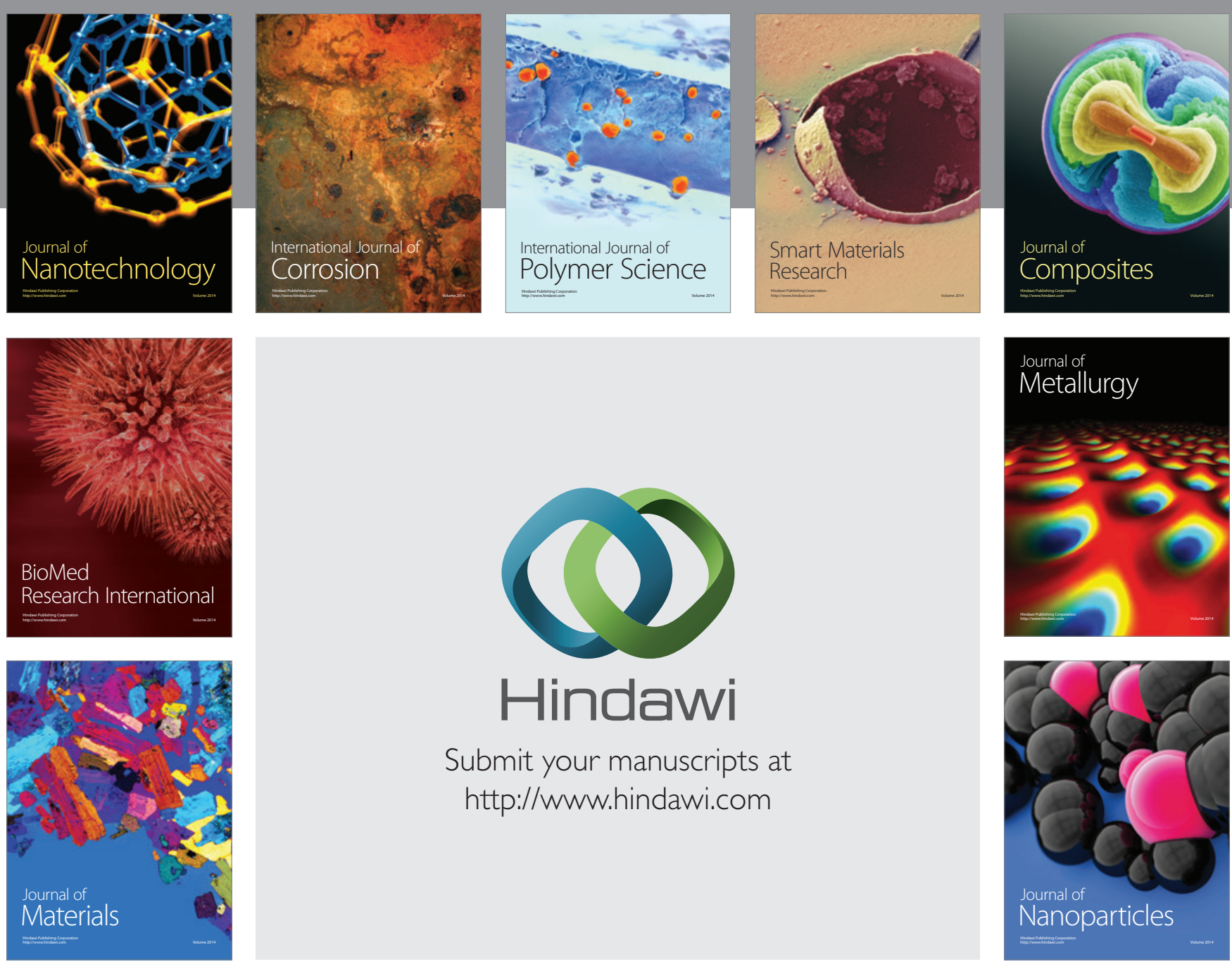

Submit your manuscripts at http://www.hindawi.com
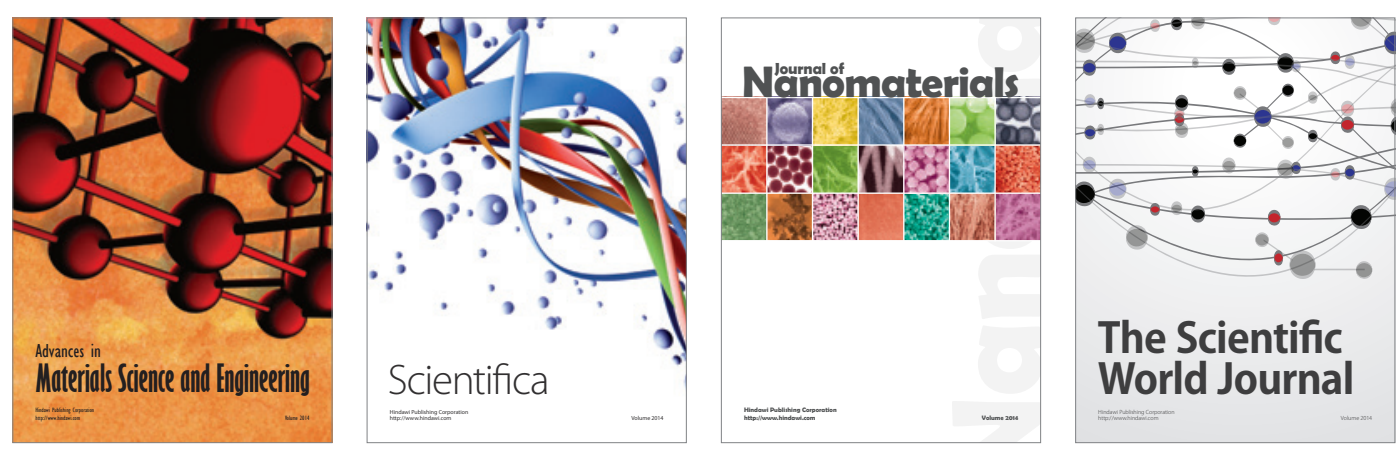

\section{The Scientific World Journal}
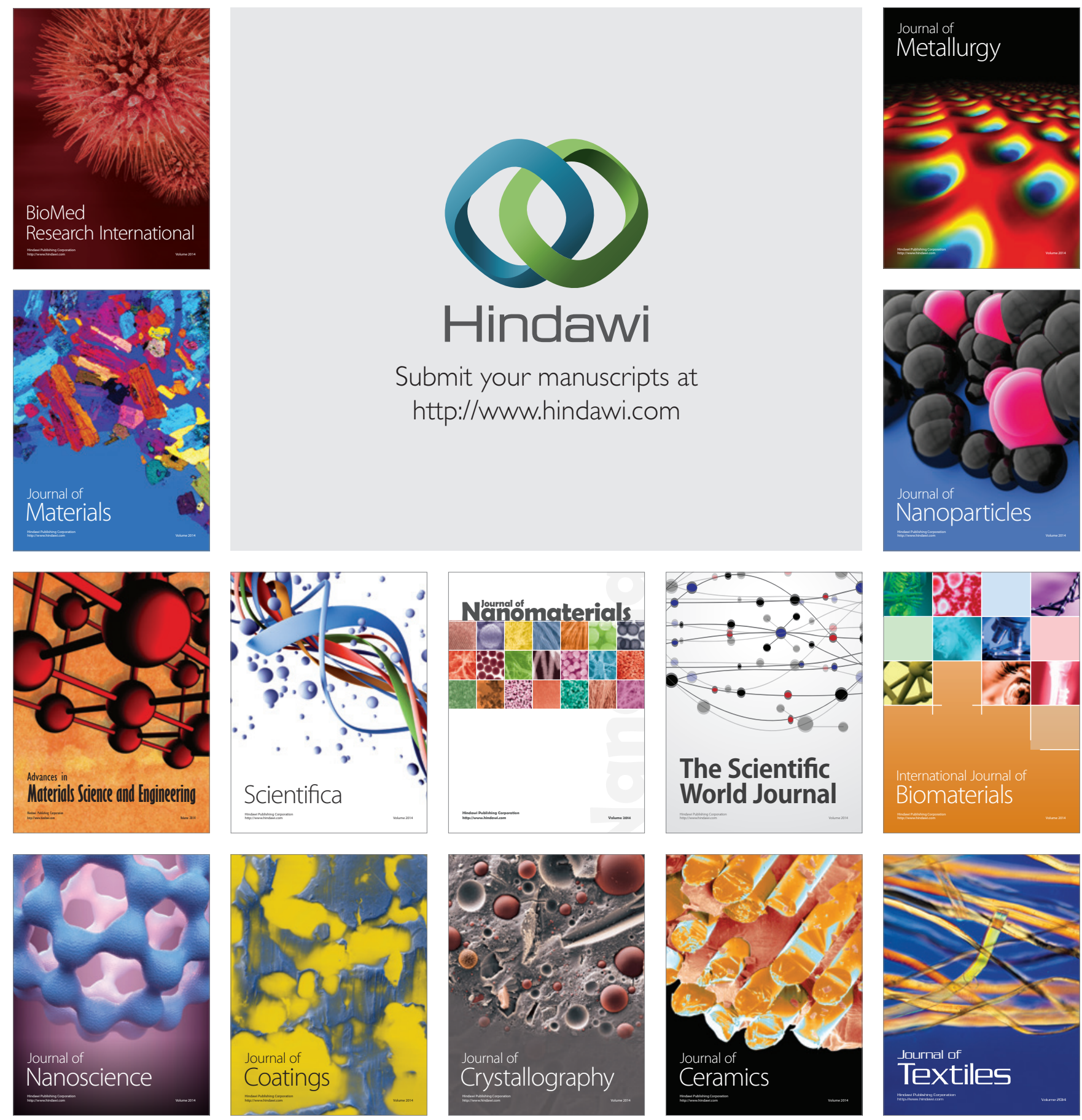